\title{
INVESTIGACIÓN/RESEARCH
}

\section{TRATAMIENTO INFORMATIVO DE UNA CRISIS DE SALUD PÚBLICA: LOS TITULARES SOBRE GRIPE A EN LA PRENSA ESPAÑOLA}

Carmen Costa-Sánchez ${ }^{1}$ : Universidad de la Coruña. España Carmen.costa@udc.es

\section{RESUMEN}

A través del análisis de los titulares publicados en un diario estatal (El País) y otro autonómico (La Voz de Galicia) pretendemos elaborar una reflexión sobre el papel de la prensa durante el primer mes de cobertura informativa de la gripe $A$, a raíz de la aparición del brote en México. La muestra investigada está formada por el conjunto de titulares de las noticias sobre gripe A publicadas en los diarios españoles y gallegos durante el plazo de un mes, en semanas consecutivas desde el inicio de la intensificación de la cobertura de prensa (considerando como tal el día 25 de abril).

PALABRAS-CLAVE: Información sobre salud - Prensa - Gripe- H1N1

\section{PUBLIC HEALTH CRISIS INFORMATIVE TREATMENT: THE HEADLINES ABOUT INFLUENZA A IN SPANISH PRESS}

\section{ABSTRACT}

Through the analysis of public ownership in a state newspaper (El Pais) and one regional (La Voz de Galicia) is to elaborate a reflection on the role of the press during the first month of coverage of influenza A, following onset of the outbreak in Mexico. The investigated sample consists of all the headlines about influenza published in Spanish and Galician newspapers during the period of one month, in consecutive weeks since the start of the intensification of media coverage (as it is the day April 25).

\footnotetext{
${ }^{1}$ Autor Correspondiente

Carmen Costa-Sánchez: Profesora de la Universidad de la Coruña.España.

Correo: Carmen.costa@udc.es
} 
KEY-WORDS: Health information - Press coverage - Influenza A- Health News

\section{INTRODUCCIÓN}

\section{Crisis de salud pública. Una propuesta de definición}

El área de salud pública trabaja con la materia prima más delicada e importante que poseemos, nuestra salud, pero no desde una perspectiva individual sino comunitaria. Por lo tanto, dada la naturaleza del servicio que se maneja, es también un sector con un alto índice de riesgo de crisis, cuyo grado de gravedad dependerá del grado de amenaza percibido.

Además, en el sector de la salud es comprensible que el nivel de exigencia de los ciudadanos sea mayor que respecto de cualquier otra actividad institucional, pues al cabo, se trata de un servicio público enfocado al cuidado del bienestar de las personas.

Por otra parte, en la "sociedad del riesgo global" (expresión acuñada por Ulrich Beck, 2002), al tiempo que se producen descubrimientos sanitarios de gran relevancia, aparecen nuevas amenazas para la salud de los individuos. Dichas amenazas se caracterizan por la expansión (internacionalización) de los riesgos y por el nivel de alarma que generan en poblaciones y gobiernos.

Si tenemos en cuenta el punto de vista de los medios de comunicación, el sector salud ha sido tradicionalmente considerado como un sector cerrado en términos de acceso y opaco en términos comunicativos. La dificultad propia del lenguaje y de los conocimientos sobre Medicina, así como la todavía escasa presencia en las redacciones de periodistas especializados en el área de salud, han contribuido en buena medida a dificultar las relaciones entre prensa y especialistas médicos.

Según explica Calvo Hernando (1997), los periodistas piden a los científicos una mayor sensibilidad ante la comunicación y la información (incluida una mayor comprensión ante las dificultades y problemas derivados de la tecnología de los medios), el uso de un lenguaje asequible, el desarrollo de sistemas de convivencia y relación y, en último término, que asuman su deber de informar al público a través de los medios de masas. Por su parte, los científicos piden a los periodistas una información objetiva y rigurosa, comprobación de fuentes y de datos y cifras, presentación del aspecto humano de los investigadores $y$, en general, respeto por lo que se ha llamado la función sagrada del conocimiento.

Recapitulando, podemos apuntar que el sector salud es un área de alto riesgo de crisis por los siguientes motivos:

a) La salud constituye un valor humano y social de gran importancia.

b) La ciudadanía se muestra exigente cuando lo que está en juego es su salud. 
c) Al tiempo que se producen avances médicos de gran calado, aparecen riesgos de nuevas y graves enfermedades.

d) Las relaciones del sector sanitario con los medios de comunicación se ven dificultadas por la complejidad del lenguaje y de los temas médicos.

Pero, ¿a qué nos referimos cuando hablamos de "crisis de salud pública"?, ¿qué caracteriza a este tipo de situaciones para que apliquemos dicha denominación? Para Churchill (2000, p. 125), una crisis de salud es un "evento no planeado que implica una amenaza real, percibida o posible contra el bienestar del público (o algún segmento de él), el ambiente o una agencia de salud afectada".

A criterio de Fita (1999, pp. 125-127), una crisis, se caracteriza por: a) Producir la alteración del normal funcionamiento de una organización debido al factor sorpresa; crear una situación de urgencia y de emergencia; b) producir corrientes de noticias negativas que necesitarán resolverse rápidamente; c) Los medios de comunicación avanzarán mucho más deprisa que la reacción de la organización, ya que tienen la posibilidad de tratar el problema en tiempo real, mientras la entidad responsable debe discernir entre descubrir las causas que produjeron el problema y atender a los medios de comunicación para dar explicaciones de un hecho del que aún no tienen los datos adecuados para pronunciarse; e) Las organizaciones se ven más obligadas a reaccionar que a tomar la iniciativa lo que provoca la desestabilización de todos los procesos comunicativos.

Echando la vista atrás, no es difícil encontrar casos de este tipo. La crisis de la empresa norteamericana Johnson \& Johnson suele citarse como paradigma de una correcta gestión de comunicación de crisis ${ }^{2}$. Trasladándonos al continente europeo, otro ejemplo acapara la atención de los teóricos: la crisis del agua Perrier ${ }^{3}$. En España, en el año 1981 se producía una de las crisis de salud más graves que conocemos, el Síndrome de Aceite Tóxico (SAT), causando la muerte de cerca de 700 personas y afectando a más de 20.000. Más recientemente, la enfermedad de las "vacas locas", por citar otro ejemplo, ponía en jaque de nuevo al Departamento de Sanidad del Gobierno español.

\footnotetext{
${ }^{2}$ En el otoño de 1982 varias personas morían en Chicago a causa del consumo de cápsulas de Tylenol que fueran envenenadas con cianuro. Según Kreps $(1990,234)$, la empresa Johnson \& Johnson, gracias al consejo de Burson-Marsteller (una asesoría de Relaciones Públicas), respondió a la crisis de la forma más efectiva y expeditiva apoyando al consumidor. La compañía retiró todas las cápsulas de Tylenol, lo que le supuso un importante coste; a través de conferencias telefónicas, les comunicó a los consumidores su nuevo paquete de triple seguridad para impedir nuevos intentos de manipulación del producto y proteger a los usuarios. El éxito en la resolución de la crisis le permitió intensificar su imagen pública como empresa socialmente responsable. La organización recibió, como reconocimiento, un premio especial Silver Anvil de la Sociedad de Relaciones Públicas de América.

3 Según relata Carrascosa (1992, 179-180) en febrero de 1990, un laboratorio de Carolina del Norte descubre restos de benceno en las botellas de agua Perrier, prototipo de bebida natural. Una semana más tarde, se encuentran restos de benceno en otra botella de Perrier en Europa. La empresa se ve obligada entonces retirar todas sus existencias de los mercados mundiales, un total de 60 millones de botellas.
} 
Desde nuestro punto de vista, llamamos "crisis de salud pública" a: aquella situación que ha provocado o puede provocar un peligro para la salud de los ciudadanos, por lo que requiere, por parte de las instituciones de una actuación pública intervencionista, mediante protocolos de protección, de seguridad y de vigilancia y de parte de los medios de comunicación un flujo de información actualizada, responsable y rigurosa.

"En salud, crisis y comunicación están íntimamente relacionadas. Todas las crisis de salud son también crisis de comunicación", se dijo en el marco del Sixth Futures Forum on Crisis Communication promovido por la Organización Mundial de la Salud (Islandia, Mayo de 2004).

Puesto que la salud es un bien colectivo, que a todos preocupa y en el que, además, somos necesariamente interdependientes a nivel glocal, la comunicación puede fácilmente llegar a convertirse en la llave para prevenir, detener o reducir un problema de salud pública.

\section{METODOLOGÍA}

En la presente investigación versa su construcción a través del método teórico del conocimiento: lógico abstracto para analizar las cualidades del objeto de investigación en todas sus dimensiones, valorar el impacto que ha generado en su contexto, en este caso la difusión de noticias sobre la gripe en dos periódicos

Se emplea además para la obtención del resultado de investigación el método de investigación cualitativa el estudio de caso.

\subsection{Estudio de caso. El papel de la prensa en los titulares de la información sobre la gripe $A$ en España}

\subsubsection{Justificación del objeto de estudio. La importancia de labor de titulación en la producción informativa}

Los titulares constituyen el escaparate mediante el cual los lectores entran o no a conocer el cuerpo de la noticia. Deben ser atractivos, pero también informar, es decir, mostrar o anunciar la esencia de la noticia. En muchas ocasiones, son la referencia informativa con la que se quedan los lectores, que no se detienen en profundizar en el resto del texto. Por ello, resulta de especial interés reflexionar sobre la calidad informativa en la titulación aplicada a las informaciones publicadas sobre gripe A en los diarios españoles y autonómicos. Los titulares cumplen tres objetivos: "anunciar y resumir la información que va en la noticia; convencer de que aquello que se cuenta es interesante; y evadirse de la propia información que resumen, cobrar vida propia, resultar inteligibles por sí mismos, de modo que el lector, apenas leído el titular, pueda ya contar el hecho". En estas tres funciones (anunciar, atraer y sintetizar) resumía Mar de Fontcuberta (1996: 117) los objetivos del titular de la noticia periodística. 
Para muchos lectores, los titulares constituyen la referencia informativa de lo que sucede en el mundo. Sus características formales contribuyen a captar la atención de la mirada del lector a través de un cuerpo de letra superior al del resto del texto, un tratamiento tipoFigura en negrita y un maquetado en una caja de texto independiente que sobrepasa la extensión de la columna periodística. En base a estas características, el atractivo visual está garantizado.

En la actualidad, además, los titulares se configuran como la parte de la noticia con mayor impacto en la audiencia, principalmente por la tendencia de una parte importante de los lectores a prestar atención sólo a la cabeza de titulación de una información (López \& Túñez, p.1995).

La responsabilidad del informador a la hora de la titulación pasa por ajustarse a la veracidad de lo acaecido, la selección de aquello que considere de mayor relevancia informativa, la coherencia entre el elemento de titulación y el resto del texto y por no atraer a los lectores con informaciones que luego no se desarrollen en el resto de la noticia (lo que calificaríamos en un lenguaje coloquial como "vender humo").

La labor de titulación constituye uno de los niveles del proceso conocido como "gatekeeping", que da lugar a la configuración del temario. Lo que se presenta como referente de realidad en cada edición del periódico no es más que la actualidad periodística, es decir, la reconstrucción de la realidad que hace cada diario; es el resultado de un proceso de inclusiones/exclusiones y jerarquizaciones de todo lo conocido por el medio.

La función de gatekeeper no está situada en un único punto de la cadena de producción informativa. En el proceso de selección, los periodistas participan activamente de dos formas distintas como gatekeeper: en el temario y en el texto. El gatekeeper, como tal, es no sólo el responsable de hacer la selección entre el total de propuestas informativas de que dispone el medio, sino también de realizar una nueva operación de selección y jerarquización a través de decidir asuntos que formarán parte de la portada y de los elementos de titulación del medio.

\subsection{Metodología aplicada}

El periodo de estudio analizado abarca del 25 de abril al 25 de mayo de 2009 de los dos diarios de mayor difusión a nivel español (El País) y gallego (La Voz de Galicia) según datos de OJD".

\footnotetext{
${ }^{4}$ Oficina de Justificación de la difusión, entidad que mide la tirada y la difusión de las publicaciones periódicas que así lo solicitan. Los datos son públicos: http://www.ojd.es
} 
Tabla 1. Datos de tirada y difusión de los diarios analizados. Elaboración propia.

\begin{tabular}{|l|r|r|l|}
\hline Diario & Tirada & Difusión & Período controlado \\
\hline El País & 508.691 & 391.815 & En-Dic 2009 \\
\hline La Voz de Galicia & 116.761 & 100.664 & En-Dic 2009 \\
\hline
\end{tabular}

Fuente: Elaboración propia

El total de titulares registrados (211) han sido categorizados mediante una ficha de análisis de contenido en los siguientes campos de estudio: El periodo de estudio analizado abarca del 25 de abril al 25 de mayo de 2009 de los

a) Ubicación: Portada o Páginas interiores y, en este último caso, Sección (Sociedad, España, Internacional, Otra).

b) Longitud: Titulares a una, dos, tres, cuatro, cinco o más columnas.

c) Presencia de antetítulo y/ o subtítulo.

1. Tipología: Los titulares fueron clasificados en cuatro posibles tipologías:

2. Titulares informativos

3. Titulares apelativos

4. Titulares temáticos

5. Titulares de Cita

d) Presencia en el grupo de titulación de palabras susceptibles de generar alarma en la población, tales como: Epidemia, pandemia, alerta, alarma, crisis o cuarentena.

e) Tema abordado, para lo que se han propuesto como categorías las siguientes:

f) Informaciones sobre contagios, evolución o historias de los contagiados.

g) Informaciones sobre el fallecimiento de personas por causa de la gripe A.

h) Informaciones con mensajes de tranquilidad para la población.

i) Informaciones sobre el funcionamiento del virus o explicación de su modus operandi.

j) Informaciones sobre la vacuna.

k) Otras informaciones.

Los titulares periodísticos han sido clasificados en cuatro grandes tipologías (que fueron recogidas por Núñez Ladeveze, 1995):

a) Títulos expresivos: Evocan, en mayor o menor grado, un hecho que se presume conocido. El periodista considera al destinatario como un experto que ya conoce aquello de lo que se habla. Ej. Victoria!

b) Títulos apelativos: Utilizan el lenguaje para llamar la atención sobre un hecho cuyo conocimiento no se presume pero del que no se informa. Ej. Espantoso 
crimen pasional en Vallecas

c) Títulos temáticos o simplificadores: Enuncian el tema de la información, sin permitir identificar la noticia. Frecuentes en las noticias sin importancia o de poco relieve.

d) Títulos informativos: Identifican una unidad de acción en el espacio tiempo.

e) Explican el sujeto de la acción, la acción misma y sus circunstancias. Son interpretables de manera autónoma, sin referencia al desarrollo informativo. Su estructura gramatical habitual es la de Sujeto + Verbo + Predicado.

A esta tipología habría que añadir la categoría de los titulares de cita, es decir, aquellos que reproducen total o parcialmente las declaraciones de la fuente de información a la que se recurre, que son especialmente habituales en el género de la entrevista.

Por su función de referente informativo de los lectores, la presente investigación centra su interés en el estudio de los titulares de prensa de los textos informativos que los diarios El País y La Voz de Galicia han publicado sobre la gripe A durante un mes a partir del 23 de abril de 2009. Es entonces cuando México confirma la existencia del brote de gripe porcina que habría matado a unas veinte personas.

La hipótesis de partida pretende confirmar o refutar la existencia de un tratamiento sensacionalista en el grupo de titulación correspondiente al conjunto de textos analizados y generados a raíz de la alarma suscitada por la gripe $\mathrm{A}$.

\section{ANÁLISIS Y DISCUSIÓN}

\subsection{Análisis cuantitativo}

Partiendo del dato más general, que consiste en haber recogido un total de 211 impactos de titulación, podemos hablar de una media de 7 impactos de titulación por día entre ambos diarios, lo que da idea de una cobertura periodística intensa, en la que obviamente ha habido altibajos, destacando la intensidad de la primera semana por oposición a la última semana analizada.

Los titulares sobre la gripe $A$ analizados estaban ubicados en Portada en un $11,37 \%$ de los casos y en Páginas interiores en el $88,62 \%$ restante. Esto significa que, durante el mes analizado, de cada diez informaciones que fueron abordadas en páginas interiores, al menos una llegó a incluirse en la jerarquía de portada.

Considerados los primeros más visibles que los segundos (pues no requieren siquiera del lector el acto de abrir el periódico y hojearlo), un $75 \%$ de los mismos son titulares de tipo informativo, mientras que el $25 \%$ restante se distribuye entre titulares apelativos, temáticos o de cita. 


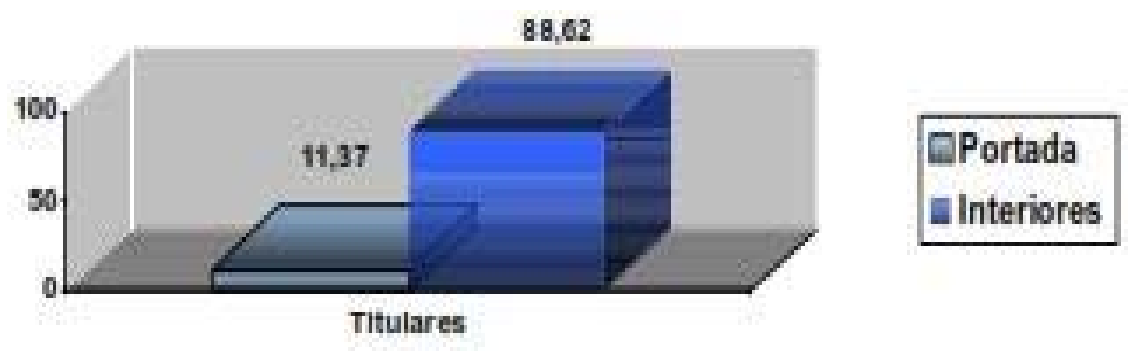

Figura 1. Presencia de titulares sobre la gripe $A$

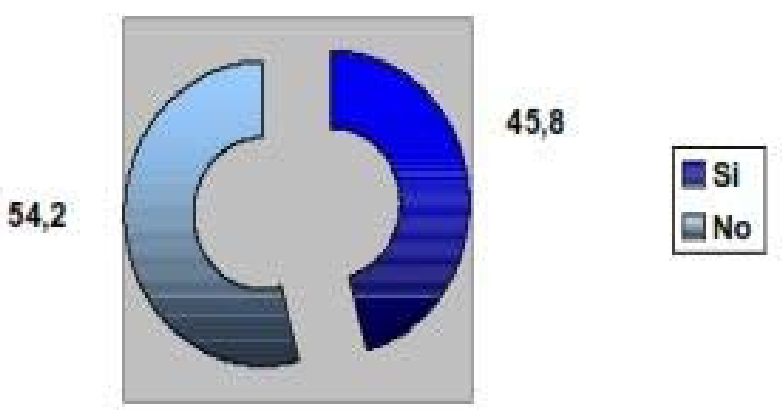

Figura 2. Presencia de palabras-alarma en portada

Del total de titulares de portada, algo menos de la mitad (un 45,8\%) incluyen alguno de los términos considerados como generadores de posible alarma en la población, esto es: epidemia, pandemia, alarma, alerta, crisis y cuarentena ${ }^{5}$.

En cuanto a la temática aludida por los titulares de portada, un $66,6 \%$ hacen referencia a la expansión de los contagios a nivel mundial, español o gallego y a las muertes a consecuencia del virus. Un $25 \%$ hace alusión a las consecuencias en las relaciones internacionales, en el tráfico aéreo y en aspectos económicos. El 8,4\% restante corresponden a mensajes de tranquilidad a la población o a noticias relacionadas con la vacuna contra el virus.

5 Debe tenerse en cuenta que la titulación de portada es redactada habitualmente por mandos intermedios, mientras que en páginas interiores sólo la supervisarían. "Podemos afirmar que la responsabilidad de titular, en general, recae sobre el estamento intermedio en mayor medida que en otros sectores de la redacción" (Zorrilla Barroso, 1996: 359). 
De los titulares de páginas interiores, la mayoría se encontraban en la sección de Sociedad $^{6}(78,67 \%)$, mientras que el $21,32 \%$ restante figuraba en la sección A Fondo del diario La Voz de Galicia. Cabe matizar que el diario El País carece de una sección diaria especializada en Ciencia o en Medicina o en Salud, circunstancia que comparte el diario gallego de referencia.

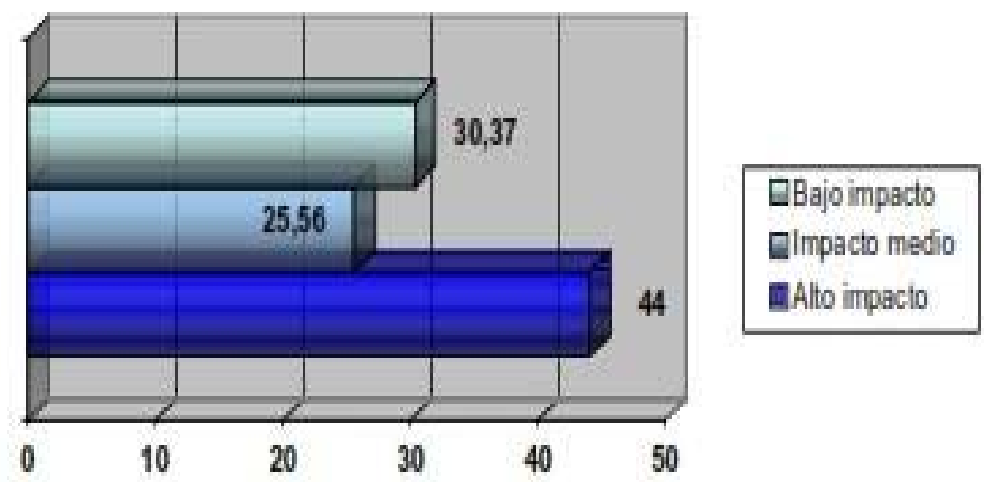

Figura 3. Longitud de los titulares

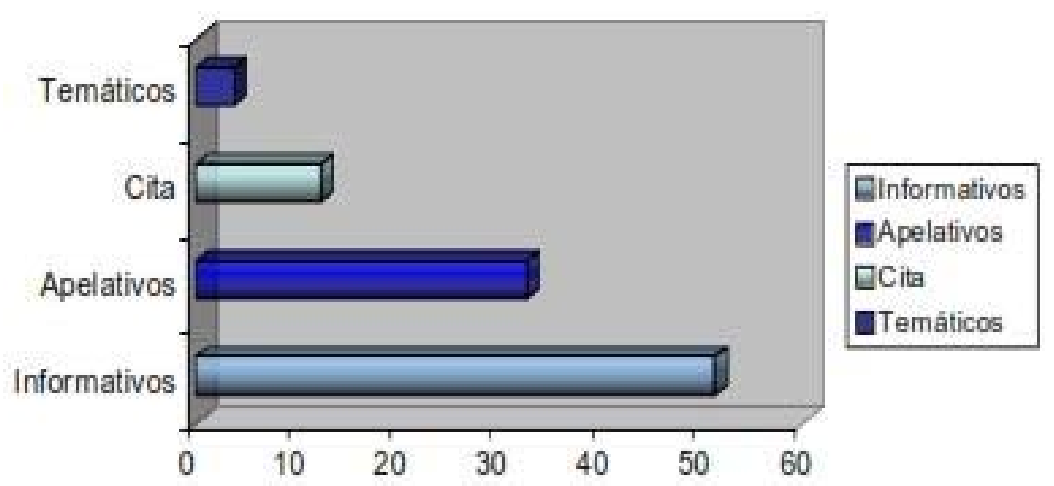

Figura 4. Tipos de titulares

En el diario El País, las informaciones se enmarcaron, bajo el cintillo de "Alerta sanitaria" ${ }^{\prime 7}$, mientras que en el diario gallego podemos hablar de una modificación del cintillo empleado con el paso del tiempo para agrupar a dichas informaciones:

a) En un primer momento se emplea el cintillo "Epidemia de gripe porcina".

b) Posteriormente pasa a ser "Alarma mundial por la gripe porcina".

c) Finalmente se configura como "Alerta mundial por la epidemia de gripe" ${ }^{\prime 8}$

\footnotetext{
${ }^{6}$ En la totalidad de los casos en el diario El País

7 En el diccionario de la Real Academia Española (RAE) podemos consultar la diferencia entre los conceptos de alarma y alerta. Se identifica la "alerta" como aquella situación de vigilancia o atención y la alarma como "inquietud, susto o sobresalto causado por algún riesgo o mal que repentinamente amenace".
} 
En cuanto al tamaño de los titulares dedicados a la gripe A y a sus consecuencias, podemos destacar que la mayoría de los titulares fueron de alto impacto visual (de 4; 5 o más columnas), concretamente un 44,07\%, seguidos por orden de frecuencia, por los titulares de bajo impacto (una o dos columnas), en un 30,37\% de los casos. Los titulares de impacto medio (a tres columnas) fueron un $25,56 \%$ del total.

Con respecto a la tipología de titulares en páginas interiores, nuevamente los titulares informativos fueron la categoría predominante $(51,18 \%)$, seguidos por los apelativos $(32,7 \%)$, los de cita $(12,3 \%)$ y los temáticos $(3,8 \%)$.

En referencia a la detección de los que llamamos "vocablos-alarma", constatamos su presencia en un $26,5 \%$ de los grupos de titulación, mientras que no fueron empleados en el $73,4 \%$ restante de los titulares de páginas interiores.

En relación con el tema aludido, los titulares que hacían referencia al nivel de contagio, a su expansión o al número de fallecidos a consecuencia del virus fueron la mayoría, un 45,01\%. Les siguen, en orden de frecuencia, aquellos que aluden a las consecuencias internacionales o económicas de la gripe, en un 40,75\% de los casos. Las alusiones a las vacunas (4,26\%) y los mensajes de tranquilidad (4,26\%) fueron minoritarias en titulares.

También aquellos relativos a la explicación del funcionamiento del virus $(3,8 \%)$.Si relacionamos, el tamaño de los titulares con la temática abordada, encontraremos que los titulares de mayor tamaño (de mayor impacto visual, esto es, a cuatro o cinco columnas) se dedican en primer término a subrayar el número/ cantidad de contagiados y muertes producidas en cualquier punto del planeta (51\%) y en segundo término, a subrayar las consecuencias negativas que está teniendo la nueva gripe en las relaciones internacionales y en aspectos económicos (34,4\%). Por el contrario, aquellos dedicados a explicar el mecanismo de funcionamiento del virus (un $2,15 \%)$ o a lanzar mensajes de tranquilidad a la población $(3,22 \%)$ son minoritarios dentro de los de mayor impacto visual.

\subsection{Análisis cualitativo. Estrategias de redacción}

Si nos detenemos más de cerca y observamos con lupa las estrategias de redacción de los titulares analizados, encontraremos algunas técnicas de redacción (o recursos literarios) que contribuyen a espectacularizar la información:

Personalización. El virus de la gripe A toma vida y se convierte en el sujeto de buena parte de los titulares analizados, tales como: "El H1N1 desata las hostilidades", "El H1N1 llega a Brasil y Argentina", "El virus da pasos de gigante", "El virus de la gripe porcina llega a España", "La gripe porcina salta fronteras", etc.

\footnotetext{
${ }^{8}$ La enfermedad es rebautizada como "gripe A", con objeto de no perjudicar a la industria cárnica, lo que provoca la adaptación del cintillo por parte del diario gallego. Esta inseguridad a la hora de acertar con el título del cintillo no deja de ser un reflejo de la incertidumbre en contexto de alerta sanitaria
} 
Empleo de terminología bélica o "de guerra". Los titulares recogen términos propios de enfrentamientos o conflictos bélicos con objeto de llamar la atención. Esto, por otra parte, puede crear en los lectores cierta sensación de inseguridad o miedo: "Los H1N1 atacan de nuevo", "Estalla la guerra del porcino", "El miedo a la pandemia asusta a las Bolsas y amenaza a la economía", "Hora de armarse contra la pandemia", "Violencia de excepción", etc.

Presencia del miedo en titulares. Además, se detectaron titulares en los cuales el miedo o la amenaza se convierten en sujeto de las informaciones. "El miedo aterriza en México", "A clase sin miedo a la gripe mala", "Del peligro de las aves a la amenaza de los cerdos", "El temor a una posible pandemia hunde las acciones de las aerolíneas y provoca el alza de las farmacéuticas", etc. Miedo, pánico, peligros y amenazas copan las primeras líneas de la titulación.

Los afectados se convierten en "marginados": Las informaciones y sus titulares reflejan la realidad marginal a la que se enfrentan los afectados. "Nos dejan la comida en la puerta de casa", "El estigma de Blanca Esther", "El avión de los apestados", "20 alumnos de una escuela de arte de Olot, en cuarentena", "El calvario de Oscarito", "La gripe fajita lleva a California una ola xenófoba contra el mexicano", "La gripe deja aislados a decenas de soldados de un cuartel de Madrid"

Gusto por las cifras. El gusto por la cifra en titulares es recurso habitual en el tratamiento informativo de la gripe A. Se recuentan afectados y víctimas como valornoticia de la información. Ello entronca con las dinámicas habituales del proceso periodístico, que valora como más riguroso aquel titular que visibiliza una cifra o un porcentaje. "México suma ya 149 muertos", "Defensa aísla a 58 militares por un posible contagio de gripe A (H1N1), "La OMS registra 79 casos en seis países", etc.

No olvidemos que las estrategias de redacción de los titulares sirven a la finalidad de captar el interés de los lectores, buscando la simplificación de la información y su presentación de un modo atractivo. En este caso, el atractivo se basa en una redacción un tanto amarilla, aunque parapetada tras una formulación informativa siguiendo la fórmula de Sujeto + Verbo + Predicado.

\section{CONCLUSIONES.}

La titulación en caso de crisis de salud pública. ¿Cómo intentar mejorarla?

Si hacemos una comparación entre los titulares de portada y los de páginas interiores, nos encontraremos que la presencia de términos que remiten al concepto de alarma o de miedo es sensiblemente más elevada en los titulares de portada que en los de páginas interiores ( $45,8 \%$ y $26,5 \%$ respectivamente).

Ello implica que los titulares con mayor impacto visual para el ciudadano, los de portada, remiten de manera directa a los conceptos de miedo, crisis, alarma y otros términos, que buscan por tanto un mayor impacto en la sensibilidad del lector. 
A la titulación de portada se añade la elección del cintillo que hacen los diarios para agrupar las distintas informaciones. En este caso, cabe diferenciar como más sobria y, en esa medida estable en el tiempo, la elegida por el diario El País a la denominación fluctuante que realiza el diario gallego.

Las temáticas aludidas por los grupos de titulación, tanto de portada como de páginas interiores fueron, por este orden:

En primer lugar, el grado de expansión de la nueva gripe a nivel mundial, que origina una dinámica contabilizadota de muertes y de afectados; cabe destacar, además, que la mayoría de los titulares más largos (a cuatro o más columnas) abordaban esta cuestión.

En segundo lugar, sus consecuencias a niveles no estrictamente sanitarios (en la vida pública, en el transporte aéreo, en el sector económico, en las relaciones internacionales, etc.);

En tercer lugar pero en porcentajes mucho menores, mensajes de tranquilidad de fuentes cuyas opiniones se consideran autorizadas (sobre todo del ámbito políticosanitario: la ministra y la consejería del ramo, pero también del estrictamente científico: investigadores, expertos en salud pública, etc.).

Para el último lugar se relegan aquellos titulares divulgativos que se acercan con afán explicativo a la naturaleza del virus de la gripe y de lo que está sucediendo.

Los titulares empleados en los textos sobre la nueva gripe no se pueden considerar mayoritariamente de tipo divulgativo. En primer lugar, hay un amplio porcentaje de titulares apelativos $(32,7 \%)$, que tienen como misión principal la de atraer la atención de los lectores.

En segundo lugar y aunque la presencia de titulares de tipo informativo es mayoritaria, su finalidad se aleja de la divulgación puesto que se corresponden con textos que anuncian la expansión del virus y sus consecuencias en términos de muertes y afectados. A nivel cualitativo, se refuerza la tesis de un estilo de redacción sensacional, en el que el virus o la gripe se convierte en un protagonista que viaja a través del mundo afectando a distintos países y causando numerosas víctimas. Esto da lugar a lo que recogen las cabeceras como una especie de guerra del mundo contra la gripe $A$, en la que debemos armarnos para luchar contra su propagación.

La prensa, por tanto, no deja de explotar lo sensacional (una enfermedad que se contagia con gran rapidez y que puede ser mortal) en los grupos de titulación. La máxima de bad news is good news se cumple, al menos, en lo que respecta a las cabeceras de titulación de los textos periodísticos analizados. 
A new cure comes along and we want to believe it. A new alarm is sounded, and we too tremble. Alarms also make good news. We too often obey a sardonic maxim: Bad news is good news; good news is no news (Cohn y Cope, 2001, 8).

Aquellos ciudadanos que hayan tomado exclusivamente los titulares como referencia informativa de la actualidad, se habrán encontrado con una reconstrucción de la actualidad un tanto alarmista y no es de extrañar que esto les haya provocado miedo o inseguridad.

Los medios de comunicación deben intentar escapar de los tratamientos sensacionalistas para, obedeciendo a su vocación de servicio público, intentar explicar contextualizadamente a los ciudadanos lo que está sucediendo.

Si el foco de su atención se centra en el número de afectados y en la cantidad de fallecidos, resultará difícil que los ciudadanos no sientan miedo ante la possible amenaza a su salud. Cierto es que la cantidad o el número de afectados es un valor noticia que ya en su día propusieron Galtung y Ruge, pero en este tipo de alarmas, debe priorizarse siempre la información útil y una tónica de calma.

Si se busca un mensaje más tranquilizador y divulgativo, así como formativo (por cuanto a la posibilidad que tienen a su alcance los medios de enseñar mecanismos preventivos a sus lectores, convirtiéndolos en agentes activos ante aquella situación que los amenaza), en ese caso, podrán contribuir al beneficio común en favor de la salud pública.

\section{BIBLIOGRAFÍA}

Beck, Ul. (2002). La sociedad del riesgo global. Madrid: Siglo XXI.

Calvo Hernando, M. (1997). Manual de periodismo científico. Barcelona: Bosch

Carrascosa, J. L. (1992). Comunicacción: una comunicación eficaz para el éxito en los negocios. Madrid: Ciencias de la Dirección.

Churchill, E. (2000). Relaciones efectivas con los medios. En E. K. Noji, (Ed.), Impacto de los desastres en la Salud Pública (pp. 122-131) Bogotá: Pan American Health Organization.

Cohn, V. (2001). News and numbers: a guide to reporting statistical claims and controversies in health and other fields. Iowa: Ames Iowa State University Press.

Fita, J. (1999). Comunicación en programas de crisis. Barcelona: Gestió

Fontcuberta, M. d. (1996). La noticia. Pistas para percibir el mundo. Barcelona: Bosch

Kreps, G. L. (1990). Organizational Communication. New York: Longman. 
López, X. \& Túñez, M. (1995). Redacción en prensa: a noticia, Santiago de Compostela: Lea.

Núñez Ladeveze, L. (1995). Introducción al periodismo escrito. Barcelona: Ariel.

World Health Organization- Europe (2009). Sixth Communication Forum, Consultado el 20 de Octubre del 2009, Disponible en: www.euro.who.int/document/E85056.pdf

Zorrilla Barroso, J. M. (1996). El titular de la noticia. Estudio de los titulares informativos en los diarios de difusión nacional. Tesis Doctoral. Universidad Complutense de Madrid, Madrid.

\section{Carmen Costa Sánchez}

Doctora en Comunicación por la Universidad de Santiago de Compostela, y licenciada en Periodismo y en Comunicación Audiovisual por la misma universidad. Sus líneas de investigación son la Comunicación para la Salud, la Comunicación Corporativa, la Comunicación en Dispositivos Móviles y los Géneros Audiovisuales. Líneas sobre las que ha publicado en diversas revistas nacionales e internacionales. En la actualidad es docente en la Facultad de Ciencias de la Comunicación, de la Universidad de la Coruña. 